
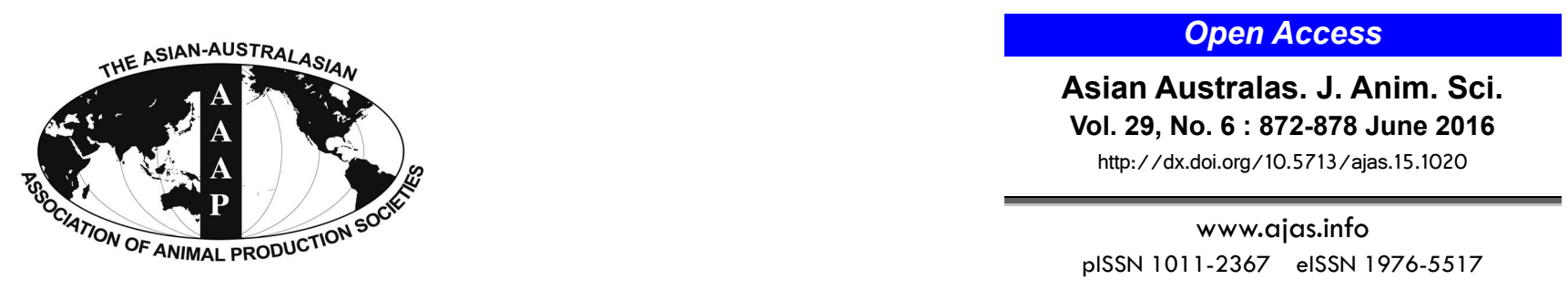

\title{
Effects of Dietary Supplementation with Astaxanthin on Histamine Induced Lesions in the Gizzard and Proventriculus of Broiler Chicks
}

\author{
Mi-hyang Ohh, Seongjin Kim ${ }^{1}$, Sok Cheon Pak ${ }^{2}$, and Kew-mahn Chee* \\ College of Life Sciences and Biotechnology, Korea University, Seoul 02841, Korea
}

\begin{abstract}
Astaxanthin (ASX) is a xanthophyll pigment isolated from crustaceans and salmonids. Owing to its powerful antioxidant activity, ASX has been reported to have the potential to protect against gastric ulcers and a variety of other illnesses. Histamine (His) is a dietary factor that causes gastric erosion and ulceration in young chicks. In this study, we examined whether ASX had protective effects on dietary histamine-induced lesions in the gizzard and proventriculus of broiler chickens. Four experimental treatment groups were planned: basal diet (BD), BD+His, BD+ASX, and BD+ASX+His, with four chicks (5 days old) in each group and three replications (i.e., a total of 12 chicks per group). The BD was supplemented with either $0.4 \%$ His or 100 ppm ASX. The birds were fed ad libitum for 3 weeks, and diets contained no antimicrobial compounds. Supplementing the diet with His significantly decreased body weight gain, but increased the weights of the gizzard and proventriculus of the chicks as compared with those of chicks in the BD group $(\mathrm{p}<0.05)$. ASX did not affect His-dependent changes in chick body weight or weights of the gizzard and proventriculus. The loss of gastric glands in the proventriculus, which was observed in His-treated chicks, was not prevented by ASX administration. The frequency of proventricular ulceration, however, was lowered by treatment with ASX, without significant differences between the two supplementation levels. In conclusion, our data showed that ASX might be helpful for alleviating structural damage to the digestive system in poultry under certain stressful conditions. (Key Words: Astaxanthin, Proventriculitis, Immunohistochemistry, Histamine, Lesion, Antioxidant)
\end{abstract}

\section{INTRODUCTION}

As a red carotenoid pigment without pro-vitamin A activity, astaxanthin (ASX) is a naturally occurring biological antioxidant found mainly in a wide variety of plants, algae, and seafoods (Nishigaki et al., 2010). Belonging to the carotenoid group and closely related to $\beta$ carotene, lutein, and zeaxanthin, ASX shares many of the general metabolic and physiological activities of other antioxidants. ASX has unique chemical properties of the hydroxyl $(\mathrm{OH})$ and keto $(\mathrm{C}=\mathrm{O})$ moieties on each ionone ring, which explains some of its unique features, namely, the high antioxidant activity (Hussein et al., 2006).

\footnotetext{
* Corresponding Author: Kew-mahn Chee. Tel: +82-2-3471-3633, Fax: +82-2-2203-7398, E-mail: cheekm@korea.ac.kr

${ }^{1}$ MILAE RESOURCES ML. Co., Ltd, Seoul 05542, Korea.

${ }^{2}$ School of Biomedical Sciences, Charles Sturt University, Bathurst, NSW 2795, Australia.

Submitted Dec. 25, 2015; Revised Dec. 28, 2015; Accepted Jan. 20, 2016
}

In recent years, a number of in vitro and in vivo studies have demonstrated the antioxidant effects of ASX. Interestingly, the antioxidant activity of ASX is a result of its quenching effects on singlet molecular oxygen, strong scavenger effects on superoxide hydrogen peroxide and/or hydroxyl radicals, and inhibitory effects on lipid peroxidation (Miki, 1991; Palozza and Krinsky, 1992). In addition, studies have shown that ASX also has several other biological activities, including anticancer (Jyonouchi et al., 2000; Kurihara et al., 2002; Hix et al., 2004; Vine et al., 2005), anti-inflammatory (Ohgami et al., 2003; Choi et al., 2008), and antidiabetic effects (Uchiyama et al., 2002; Naito et al., 2004). Furthermore, ASX has beneficial effects on the skin (Lyons and O'Brien, 2002), reproduction (Comhaire and Mahmoud, 2003), and blood pressure (Hussein et al., 2005a, b). While the effects of ASX in mammals have not been well characterized, ASX has also been shown to prevent aflatoxin-induced toxicity in mule ducklings (Cheng et al., 2001). Thus, ASX supplementation 
may have benefits for poultry production sustainability.

A major recurrent problem facing the poultry industry is the incidence of proventricular lesions, including proventricular enlargement and/or other pathologies associated with proventriculitis (Bayyari et al., 1995). These pathologies can result in decreased feed efficiency, decreased weight gain, and increased carcass contamination from gastrointestinal rupture during processing. Similar observations have been attributed to a number of causative agents, including biogenic amines (Barnes et al., 2001), mycotoxins (Pegram and Wyatt, 1981), copper sulphate (Wideman et al., 1995), and an unidentified filterable infectious agent (Bayyari et al., 1995), although it is likely that none of these agents is solely responsible for proventriculitis.

Biogenic amines, such as histamine (His), cadaverine, putrescine, spermine, and spermidine, are breakdown products that are produced during decarboxylation of amino acid catabolism. Biogenic amines have been shown to decrease feed efficiency (Brugh and Wilson, 1986; Stuart et al., 1986) and induce proventricular hyperplasia (Tucker et al., 1975), thereby compromising growth performance (Barnes et al., 2001). His also acts to stimulate gastric acid secretion from the parietal cells through the $\mathrm{H} 2$ receptors, and if dietary His exceeds the capacity for degradation, it may cause continuous stimulation of gastric acid secretion with subsequent gizzard erosion (Masumura et al., 1985). In humans, His affects circulation, gastric acid secretion, neurotransmission, and cell growth. Physical and psychological stresses also induce gastric damage, and many reports have demonstrated that reactive oxygen species cause intestinal ulceration (Das and Banerjee, 1993).

Several studies have investigated the effects of vitamins $\mathrm{C}$ and $\mathrm{E}$ against gastric ulcers caused by a variety of oxidative damages. Ascorbic acid (vitamin C) has been reported to spontaneously degrade His in the presence of molecular oxygen and copper ions (Chatterjee et al., 1975; Uchida et al., 1989). In species that are reliant on dietary vitamin $\mathrm{C}$, such as humans and guinea pigs, His levels in tissues are inversely related to vitamin $\mathrm{C}$ status (Chatterjee et al., 1975; Clemetson, 1980; Johnston and Huang, 1991). Some studies have examined the potential interactions between ASX and natural antioxidants. The combination of ASX and $\alpha$-tocopherol ameliorates oxidative injury through suppression of oxidative stress induced by diabetes (Nakano et al., 2008). Moreover, the antioxidant synergism of vitamin $\mathrm{E}$ and ASX was supported by decreased malondialdehyde levels (Bell et al., 2000). Thus, ASX would be expected to be a useful antioxidant for the prevention of oxidative stress. For example, ASX inhibits stress-induced impairment of antitumor activity in NK cells via its antioxidative properties, which may explain its inhibitory effects on cancer metastasis (Kurihara et al., 2002).

Despite the importance of ASX in normal physiological function and its potential involvement in pathological conditions, few studies have examined the possible interaction between His and ASX. Therefore, the objective of the current study was to investigate whether ASX had protective effects against His-induced lesions in the gizzard and proventriculus of broiler chicks. Markers of growth performance (body weight gain, feed intake, and feed conversion ratio), lesions (incidence and scores), and oxidative stress (lipid peroxidation and antioxidant enzymes) were evaluated as indicators of His exposure.

\section{MATERIALS AND METHODS}

\section{Birds and housing}

One-day-old broiler chicks (Ross 308) were obtained from a commercial hatchery (PyungTaek, Korea). They were housed in electrically heated incubators with water and a commercial broiler diet available ad libitum until they were used for experiments. At the beginning of each experiment, 48 chicks were selected from a two-fold larger population to obtain uniformity of body weight among the birds. Light was provided $23 \mathrm{~h} / \mathrm{d}$ throughout the experimental period. All animal experiments were conducted in accordance with established guidelines and were approved by the Animal Care and Use Committee of Korea University.

\section{Diets and experimental design}

A commercial broiler starter diet $(20 \%$ crude protein and 3,180 kcal metabolizable energy/kg) was used as a basal diet (BD). Birds were fed a $\mathrm{BD}$, a diet containing $0.4 \%$ His (BD+His), a diet containing $100 \mathrm{ppm}$ ASX (BD+ASX), or a diet of 100 ppm ASX plus $0.4 \%$ His (BD+ASX+His) from 5 to 26 days of age ad libitum. The ASX content of the freeze-dried Phaffia yeast was $5.0 \mathrm{mg} / \mathrm{g}$ yeast. Four 5-day-old chicks were allocated to each of the four experimental treatment groups, and the experiment was replicated three times. Doses of His and ASX were based on preliminary dose estimation.

\section{Sampling}

At the end of the experiment, the chicks and feed were weighed to determine body weight gain and feed consumption during the experiment. Blood was collected from the wing vein with heparin as the anticoagulant and centrifuged for $15 \mathrm{~min}$ at $1,500 \times \mathrm{g}$. The plasma was stored at $-70^{\circ} \mathrm{C}$ for later analyses. All chicks were sacrificed by cervical dislocation, and the organs were weighed. The proventriculus and gizzard were removed and fixed in $10 \%$ 
buffered formalin for histology and histochemistry analyses.

\section{Chemical analyses}

ASX content in the plasma and tissue was analyzed according to the methods described by Akiba et al. (2001). Briefly, $200 \mu \mathrm{L}$ plasma and $0.5 \mathrm{~g}$ tissue were added to a hexane-ethanol $(1: 1 \mathrm{v} / \mathrm{v})$ solution and centrifuged at 1,500 $\mathrm{rpm}$ for $10 \mathrm{~min}$. Cleared supernatants were collected, filtered, and injected directly for analysis by highperformance liquid chromatography (HPLC). ASX purchased from Sigma (98\% purity; St. Louis, MO, USA) was used as an external standard.

Plasma vitamin E was analyzed according to the methods described by Desai (1984). In brief, $200 \mu \mathrm{L}$ plasma was added to $2 \mathrm{~mL}$ of $2 \%$ pyrogallol, mixed, and incubated at $-70^{\circ} \mathrm{C}$ for $30 \mathrm{~min}$. After addition of $1 \mathrm{~mL}$ distilled water and $4 \mathrm{~mL}$ hexane, the mixture was centrifuged at $1,500 \mathrm{rpm}$ for $20 \mathrm{~min}$. Cleared supernatants were then dried with nitrogen gas, dissolved in hexane, and subjected to HPLC for analysis.

Tissue vitamin $\mathrm{E}$ was also analyzed according to the methods described by Desai (1984). Briefly, tissue was homogenized using 5 volumes of $1.15 \% \mathrm{KCl}$, and $1.0 \mathrm{~mL}$ ethanol, $0.5 \mathrm{~mL}$ of $25 \%$ ascorbic acid, and $1 \mathrm{~mL}$ of $10 \mathrm{~N}$ $\mathrm{KOH}$ were then added. The mixture was incubated at $-70^{\circ} \mathrm{C}$ for $30 \mathrm{~min}$. After adding $4 \mathrm{~mL}$ hexane, the mixture was centrifuged at $1,500 \mathrm{rpm}$ for $10 \mathrm{~min}$, and cleared supernatants were analyzed using HPLC. The mobile phase was composed of methanol and water (98:2) applied at a flow rate of $1 \mathrm{~mL} / \mathrm{min}$, and the detection wavelength was $293 \mathrm{~nm}$.

Plasma and tissue vitamin $\mathrm{C}$ concentrations were analyzed as described previously (Omaye et al., 1979). In brief, either $400 \mu \mathrm{L}$ plasma or $0.4 \mathrm{~mL}$ tissue homogenate was added into ice-cold $10 \%$ trichloroacetic acid, mixed, and centrifuged at $3,500 \mathrm{rpm}$ for $20 \mathrm{~min}$. Next, $500 \mu \mathrm{L}$ of the supernatant was added into $0.1 \mathrm{~mL}$ 2,4dinitrophenylhydrazine/thiourea/copper sulphate solution and incubated at $37^{\circ} \mathrm{C}$ for $3 \mathrm{~h}$. After further addition of 0.75 $\mathrm{mL}$ of $65 \%$ sulphuric acid, the absorbance was measured at $520 \mathrm{~nm}$. Plasma and liver superoxide dismutase (SOD) activities were analyzed by the formazan-WST method (Total SOD Assay Kit; Dojindo Laboratories, Tabaru, Japan). SOD activity was calculated as follows: percent inhibition (\%) $=\left(\left[\mathrm{A}_{\text {blank }}-\mathrm{A}_{\text {sample }}\right] / \mathrm{A}_{\text {blank }}\right) \times 100$ where $\mathrm{A}_{\text {blank }}$ and $\mathrm{A}_{\text {sample }}$ are the absorbance values of the blank and sample, respectively.

Lipid peroxidation was determined as thiobarbituric acid reactive substances (TBARS) using the HPLCfluorescence method. TBARS concentrations were determined from a standard curve established with TBAmalondialdehyde (MDA, 1,1,3,3-tetramethoxypropane) adducts.

For histological studies, small pieces of proventriculus and gizzard were embedded in paraffin blocks. The sections were then stained with hematoxylin-eosin dye, as described previously (Sibilia et al., 2003) followed by light microscopy observations at $10 \times$ magnification. For immunohistochemistry, the proventriculus and gizzard were removed, cut into sagittal slices (4 mm thick), and fixed overnight with $10 \%$ formalin solution.

The fixed proventriculus and gizzard slices were routinely processed, embedded in paraffin, and sectioned to 7- $\mu \mathrm{m}$ thickness. Hematoxylin-eosin staining was performed to examine histopathological changes. Sections were deparaffinized in xylene, rehydrated in a graded alcohol series, incubated in a solution of $3 \%$ hydrogen peroxide in methanol for $30 \mathrm{~min}$, and microwaved at $750 \mathrm{~W}$ for $10 \mathrm{~min}$ in $10 \mathrm{nM}$ citrate buffer (pH 6.0). Nonspecific binding sites were blocked with normal rabbit serum diluted 1:10 in phosphate-buffered saline (PBS) for $30 \mathrm{~min}$ and incubated overnight at $4^{\circ} \mathrm{C}$ with primary antiserum. After rinsing in PBS, sections were incubated in biotinylated secondary antibody (Vector Laboratories, Burlingame, CA, USA) for $30 \mathrm{~min}$. The antigen-antibody complex was visualized by an avidin-biotin-peroxidase complex solution (Vector Laboratories, USA) with 3,3-diamino benzidine (Invitrogen, Carlsbad, CA, USA). Tissue sections were then rinsed in distilled water and counter stained with Mayer's hematoxylin.

\section{Statistical analysis}

The results are presented as means \pm standard errors. Data were analyzed using Duncan's test, and differences with $p$ values of less than 0.05 were considered significant.

\section{RESULTS}

Body weight gain, feed intake, and feed conversion ratios are summarized in Table 1. Birds fed a diet supplemented with ASX had the highest body weight gain and feed intake, while those consuming His ate less and weighted the least. However, birds consuming a diet

Table 1. Growth performance in broiler chicks fed a diet supplemented with $100 \mathrm{ppm}$ astaxanthin or $0.4 \%$ histamine from day 5 to day $26^{1}$

\begin{tabular}{lrcc}
\hline Treatment $^{2}$ & $\begin{array}{r}\text { Body weight } \\
\text { gain }(\mathrm{g} / \mathrm{b} \text { /rd })\end{array}$ & $\begin{array}{c}\text { Feed intake } \\
(\mathrm{g} / \mathrm{b} \text { ird })\end{array}$ & $\begin{array}{c}\text { Feed } \\
\text { conversion ratio }\end{array}$ \\
\hline $\mathrm{BD}$ & $978.6 \pm 69.2^{\mathrm{b}}$ & $1,566.2 \pm 116.9^{\mathrm{a}}$ & $1.60 \pm 0.02^{\mathrm{b}}$ \\
$\mathrm{BD}+\mathrm{His}$ & $593.8 \pm 45.8^{\mathrm{c}}$ & $1,076.8 \pm 71.1^{\mathrm{b}}$ & $1.82 \pm 0.04^{\mathrm{a}}$ \\
$\mathrm{BD}+\mathrm{ASX}$ & $1,135.1 \pm 29.7^{\mathrm{a}}$ & $1,702.1 \pm 31.9^{\mathrm{a}}$ & $1.50 \pm 0.05^{\mathrm{b}}$ \\
$\mathrm{BD}+\mathrm{ASX}+\mathrm{His}$ & $586.1 \pm 36.8^{\mathrm{c}}$ & $1,030.4 \pm 38.1^{\mathrm{b}}$ & $1.76 \pm 0.05^{\mathrm{a}}$ \\
\hline
\end{tabular}

${ }^{1}$ Values are means \pm standard errors for body weight gain, feed intake, and feed conversion ratio.

${ }^{2}$ Four experimental diets: $\mathrm{BD}=$ basal diet; $\mathrm{BD}+\mathrm{His}=$ basal $\operatorname{diet}+0.4 \%$ histamine; $\mathrm{BD}+\mathrm{ASX}=$ basal diet+astaxanthin; $\mathrm{BD}+\mathrm{ASX}+\mathrm{His}=$ basal diet+astaxanthin $+0.4 \%$ histamine.

a-c Values within the same column sharing no common superscript differ significantly $(\mathrm{p}<0.05)$. 
Table 2. Effects of diet supplemented with astaxanthin or histamine on relative organ/weight ratio in broiler chicks ${ }^{1}$

\begin{tabular}{lccccccc}
\hline Treatment $^{2}$ & Liver & PV+GI & Pancreas & Spleen $(\mathrm{g} / 100 \mathrm{~g})$ & Heart & Fabricius & AF \\
\hline BD & $2.83 \pm 0.07^{\mathrm{a}}$ & $1.91 \pm 0.06^{\mathrm{b}}$ & $0.23 \pm 0.01^{\mathrm{b}}$ & $0.09 \pm 0.00^{\mathrm{a}}$ & $0.82 \pm 0.02^{\mathrm{a}}$ & $0.24 \pm 0.01^{\mathrm{b}}$ & $1.47 \pm 0.09^{\mathrm{a}}$ \\
$\mathrm{BD}+$ His & $2.92 \pm 0.11^{\mathrm{a}}$ & $3.16 \pm 0.19^{\mathrm{a}}$ & $0.35 \pm 0.01^{\mathrm{a}}$ & $0.06 \pm 0.01^{\mathrm{b}}$ & $0.82 \pm 0.03^{\mathrm{a}}$ & $0.21 \pm 0.02^{\mathrm{b}}$ & $0.73 \pm 0.10^{\mathrm{b}}$ \\
$\mathrm{BD}+$ ASX & $2.77 \pm 0.13^{\mathrm{a}}$ & $1.60 \pm 0.09^{\mathrm{b}}$ & $0.24 \pm 0.02^{\mathrm{b}}$ & $0.08 \pm 0.01^{\mathrm{ab}}$ & $0.74 \pm 0.03^{\mathrm{a}}$ & $0.26 \pm 0.02^{\mathrm{ab}}$ & $1.57 \pm 0.18^{\mathrm{a}}$ \\
$\mathrm{BD}+\mathrm{ASX}+$ His & $2.58 \pm 0.08^{\mathrm{a}}$ & $3.39 \pm 0.25^{\mathrm{a}}$ & $0.33 \pm 0.01^{\mathrm{a}}$ & $0.07 \pm 0.01^{\mathrm{ab}}$ & $0.79 \pm 0.03^{\mathrm{a}}$ & $0.30 \pm 0.02^{\mathrm{a}}$ & $0.70 \pm 0.13^{\mathrm{b}}$ \\
\hline
\end{tabular}

PV, proventriculus; GI, gizzard; AF, abdominal fat.

${ }^{1}$ Values are means \pm standard errors for organ/weight ratio.

${ }^{2}$ Four experimental diets: $\mathrm{BD}=$ basal diet; $\mathrm{BD}+\mathrm{His}=$ basal diet $+0.4 \%$ histamine; $\mathrm{BD}+\mathrm{ASX}=$ basal diet + astaxanthin; $\mathrm{BD}+\mathrm{ASX}+\mathrm{His}=\mathrm{basal}$ diet+astaxanthin $+0.4 \%$ histamine.

${ }^{\mathrm{a}-\mathrm{c}}$ Values within the same column sharing no common superscript differ significantly $(\mathrm{p}<0.05)$.

containing both His and ASX exhibited the least growth efficiency in terms of body weight gain and feed intake. Addition of ASX to the diet caused chicks to consume less feed per gram gain than other treatments. These data indicated that birds consuming ASX were able to convert feed to growth more efficiently.

With regard to organ/weight ratio, none of the diets affected the fresh weights of the liver, spleen, heart, and fabricius (Table 2). Supplementation with His resulted in enlargement of the proventriculus, gizzard, pancreas, and abdominal fat, and the addition of ASX did not alleviate His-induced organ enlargement.

The plasma concentration of vitamin $\mathrm{C}$ was not affected by supplementation with ASX or His, whereas hepatic vitamin $\mathrm{C}$ level increased more with ASX than other supplementations (Table 3). Dietary ASX or His had lowering effects on plasma and liver vitamin $\mathrm{E}$ concentrations compared to the dietary BD.

The effects of dietary supplementation with ASX or His on lesions associated with proventriculus are shown in Table 4. Higher lesion scores were consistently observed in chicks consuming dietary His compared with those consuming the BD. Interestingly, supplementation with ASX resulted in a lower incidence of lesions and reduced lesion scores. When the BD was supplemented with ASX and His, however, the effects of ASX on reducing the incidence of proventricular lesions was not obvious.

SOD and TBARS are extensively used as biochemical indicators of the pathological states associated with oxidative stress and lipid peroxidation, respectively. His
Table 4. Effects of dietary astaxanthin or histamine on proventricular lesions (PLs) in broiler chicks

\begin{tabular}{lcccccc}
\hline \multirow{2}{*}{ Treatment $^{1}$} & \multicolumn{4}{c}{$\begin{array}{c}\text { PL intensity and } \\
\text { number involved }\end{array}$} & PL & Occurrence of \\
\cline { 2 - 5 } & 1 & 2 & 3 & 4 & & \\
\hline BD & 8 & 2 & 2 & 0 & 6 & $2 / 12$ \\
BD+His & 5 & 4 & 1 & 1 & 9 & $2 / 11$ \\
BD+ASX & 8 & 2 & 0 & 0 & 2 & $0 / 10$ \\
BD+ASX+His & 8 & 2 & 2 & 0 & 6 & $2 / 12$ \\
\hline
\end{tabular}

${ }^{1}$ Four experimental diets: $\mathrm{BD}=$ basal diet; $\mathrm{BD}+\mathrm{His}=$ basal diet $+0.4 \%$ histamine; $\mathrm{BD}+\mathrm{ASX}=$ basal diet+astaxanthin; $\mathrm{BD}+\mathrm{ASX}+\mathrm{His}=$ basal diet+astaxanthin $+0.4 \%$ histamine.

${ }^{2}$ Intensity 1 , no abnormalities and lesion is minor; intensity 2, mild lesion; intensity 3, moderate lesion; intensity 4: severe lesion.

${ }^{3}$ PL score $=$ PL intensity $\times$ number of chicks involved.

supplementation caused a reduction in SOD levels in the blood, while the opposite effect was observed for dietary ASX (Table 5). In contrast, none of the dietary treatments caused significant alterations in SOD activities in the liver. His supplementation significantly altered lipid peroxidation in the liver, while ASX did not prevent the increase in MDA (Table 5). Neither His nor ASX changed the level of MDA in the blood.

Figure 1A shows the extent of lesions in the mucosal layer of the proventriculus stained with hematoxylin-eosin. While no mucosal damage was observed in the BD group, His caused severe mucosal ulcerative lesions in the mucosal epithelium and lamina propria of the proventriculus. In contrast, in chicks treated with ASX, unique degeneration

Table 3. Effects of astaxanthin or histamine supplementation on plasma and liver concentrations of vitamins $\mathrm{C}$ and $\mathrm{E}$ in broiler chicks ${ }^{1}$

\begin{tabular}{|c|c|c|c|c|c|c|}
\hline \multirow{2}{*}{ Treatment $^{2}$} & \multicolumn{3}{|c|}{ Plasma } & \multicolumn{3}{|c|}{ Liver } \\
\hline & $\operatorname{ASX}(\mu \mathrm{g} / \mathrm{dL})$ & Vitamin $C(\mu \mathrm{g} / \mathrm{mL})$ & Vitamin $E(\mu \mathrm{g} / \mathrm{mL})$ & $\operatorname{ASX}(\mu \mathrm{g} / \mathrm{mg})$ & Vitamin $C(\mu \mathrm{g} / \mathrm{mg})$ & Vitamin $\mathrm{E}(\mu \mathrm{g} / \mathrm{mg})$ \\
\hline $\mathrm{BD}$ & - & $25.8 \pm 2.23^{\mathrm{a}}$ & $31.9 \pm 4.08^{\mathrm{a}}$ & - & $237.9 \pm 9.99^{b}$ & $47.8 \pm 4.55^{\mathrm{a}}$ \\
\hline $\mathrm{BD}+\mathrm{His}$ & - & $21.6 \pm 1.04^{\mathrm{a}}$ & $18.6 \pm 5.13^{b}$ & - & $203.9 \pm 4.64^{c}$ & $29.9 \pm 4.00^{\mathrm{b}}$ \\
\hline $\mathrm{BD}+\mathrm{ASX}$ & $6.25 \pm 0.56^{\mathrm{a}}$ & $25.4 \pm 1.78^{\mathrm{a}}$ & $19.4 \pm 2.53^{b}$ & $1.13 \pm 0.11^{\mathrm{a}}$ & $267.5 \pm 10.19^{a}$ & $39.5 \pm 3.77^{\mathrm{ab}}$ \\
\hline $\mathrm{BD}+\mathrm{ASX}+\mathrm{His}$ & $1.09 \pm 0.12^{\mathrm{b}}$ & $26.5 \pm 1.16^{\mathrm{a}}$ & $14.8 \pm 2.21^{\mathrm{b}}$ & $0.40 \pm 0.03^{b}$ & $199.9 \pm 4.96^{\mathrm{c}}$ & $27.9 \pm 4.50^{\mathrm{b}}$ \\
\hline
\end{tabular}

ASX, astaxanthin.

${ }^{1}$ Values are means \pm standard errors.

2 Four experimental diets: $\mathrm{BD}=$ basal diet; $\mathrm{BD}+\mathrm{His}=$ basal diet $+0.4 \%$ histamine; $\mathrm{BD}+\mathrm{ASX}=$ basal diet + astaxanthin; $\mathrm{BD}+\mathrm{ASX}+\mathrm{His}=$ basal diet+astaxanthin $+0.4 \%$ histamine.

${ }^{a-c}$ Values within the same column sharing no common superscript differ significantly $(\mathrm{p}<0.05)$. 
Table 5. Effects of astaxanthin or histamine supplementation on plasma and liver concentrations of SOD and MDA in broiler chicks ${ }^{1}$

\begin{tabular}{|c|c|c|c|c|}
\hline \multirow{3}{*}{ Treatment $^{2}$} & \multicolumn{2}{|c|}{ SOD } & \multicolumn{2}{|c|}{ TBARS } \\
\hline & Liver & Plasma & \multirow{2}{*}{$\frac{\text { Liver }}{\text { MDA (ng/mg) }}$} & \multirow{2}{*}{$\frac{\text { Plasma }}{\text { MDA }(\mathrm{ng} / \mathrm{mL})}$} \\
\hline & \multicolumn{2}{|c|}{ Inhibition rate $(\%)$} & & \\
\hline$\overline{\mathrm{BD}}$ & $63.6 \pm 1.62^{\mathrm{a}}$ & $66.8 \pm 2.63^{\mathrm{b}}$ & $0.86 \pm 0.03^{\mathrm{d}}$ & $0.51 \pm 0.05^{\mathrm{a}}$ \\
\hline $\mathrm{BD}+\mathrm{His}$ & $63.4 \pm 1.26^{\mathrm{a}}$ & $78.2 \pm 2.39^{\mathrm{a}}$ & $1.68 \pm 0.08^{b}$ & $0.46 \pm 0.04^{\mathrm{a}}$ \\
\hline $\mathrm{BD}+\mathrm{ASX}$ & $67.7 \pm 1.41^{\mathrm{a}}$ & $56.2 \pm 1.72^{\mathrm{c}}$ & $1.16 \pm 0.05^{\mathrm{c}}$ & $0.62 \pm 0.08^{\mathrm{a}}$ \\
\hline $\mathrm{BD}+\mathrm{ASX}+\mathrm{His}$ & $65.8 \pm 1.16^{\mathrm{a}}$ & $71.5 \pm 2.28^{b}$ & $2.50 \pm 0.11^{\mathrm{a}}$ & $0.64 \pm 0.09^{\mathrm{a}}$ \\
\hline
\end{tabular}

SOD, superoxide dismutase; MDA, malondialdehyde; TBARS, thiobarbituric acid reactive substances.

${ }^{1}$ Values are means \pm standard errors.

${ }^{2}$ Four experimental diets: $\mathrm{BD}=$ basal diet; $\mathrm{BD}+\mathrm{His}=$ basal diet $+0.4 \%$ histamine; $\mathrm{BD}+\mathrm{ASX}=$ basal diet+astaxanthin; $\mathrm{BD}+\mathrm{ASX}+\mathrm{His}=$ basal diet+astaxanthin $+0.4 \%$ histamine.

${ }^{\mathrm{a}-\mathrm{d}}$ Values within the same column sharing no common superscript differ significantly $(\mathrm{p}<0.05)$.

and necrosis of the epithelium were not observed. Further examination of the proventriculus with SOD immunoperoxidase staining (figure not shown) revealed that ASX reduced the His-dependent increase in SOD expression in the gastric mucosal layer. The extent of lesions in the mucosal layer of the gizzard is shown in Figure 1B. In contrast to the results in the BD group, His supplementation resulted in the formation of severe lesions of vesicular enlargement in the mucosa of the gizzard. ASX treatment led to recovery of normal vesicles.

\section{DISCUSSION}

In this study, we investigated whether ASX had protective effects against His-induced lesions in the gizzard and proventriculus of broiler chicks. Our data demonstrated that ASX lowered the frequency of proventricular ulceration induced by His, indicating that ASX may be useful for alleviating structural damage to the digestive system in poultry under certain stressful conditions.

ASX, one of the most common carotenoids, exerts powerful antioxidant properties by cleavage of singlet oxygen. Therefore, ASX protects many tissues from lipid peroxidation in mammals (Goto et al., 2001; Hussein et al., 2006). However, our current results indicated that feeding a diet supplemented with ASX and His was not effective for the prevention of lipid peroxidation estimated by MDA production, as measured by determining TBARS levels. On the other hand, antioxidative enzymes, such as SOD, can scavenge radicals and contribute to the body's defenses against oxidative stress. In particular, SODs catalyze the dismutation of superoxide and hydrogen peroxide, the first step of enzymatic antioxidative defenses. Dietary supplementation with ASX and His resulted in a significant inhibition of plasma SOD activity compared with that of His supplementation alone. Hence, increased SOD expression may neutralize the harmful effects of superoxides from His during the early stress response in the plasma. Contrary to the findings that exogenously administered ASX can be incorporated into microsomes of the liver tissue and other organs in male broiler chicks (Takahashi et al., 2004), ASX was not incorporated into the liver in our study, and thus, did not prevent lipid peroxidation in chicks, probably due to the gender factor of chicks and the preparation of ASX.

Growth performance was significantly increased by

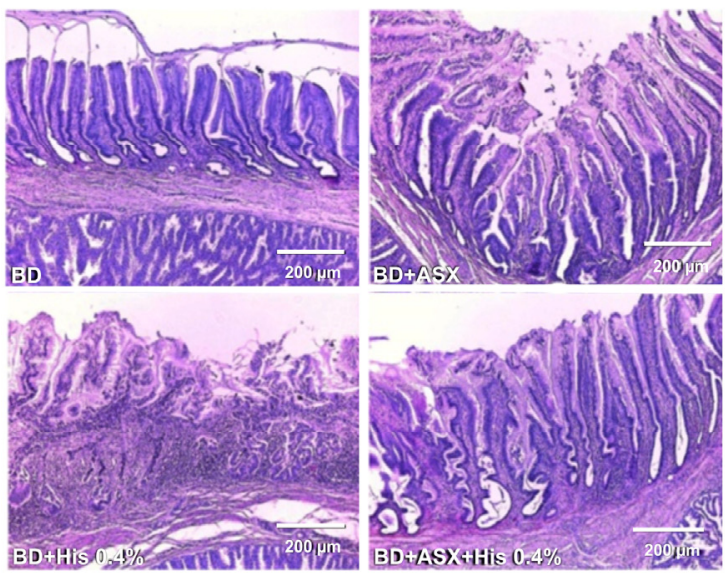

(A)

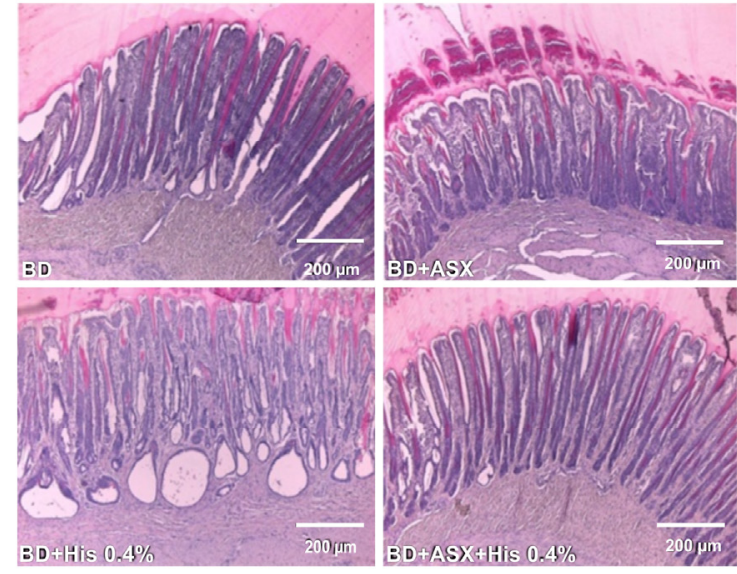

(B)

Figure 1. Histologic examination of the proventriculus (A) and gizzard (B) from chicks treated with His and ASX. Hematoxylin-eosin staining was used. Scale bar: $200 \mu \mathrm{m}$. Magnification, $10 \times$. 
supplementation with ASX in the current study. Although data describing the effects of ASX on growth performance are conflicting, it is possible that ASX stimulates feed intake via its known anti-inflammatory effects. In fact, Cheng et al. (2001) found that ASX alleviated growth retardation by enhancing the chemotaxis ability of macrophages under aflatoxin-induced toxicity in mule ducklings. This theory was further supported by the enhancement of antibody production and proliferation of $\mathrm{T}$ cells as the centrepiece of immune function by ASX feeding (Takimoto et al., 2007). However, our data describing the growth performance of chicks showed that supplementation with ASX was not efficacious in the feed conversion ratio when the diet was supplemented with His. While the reason for this discrepancy is not clear, ASX supplementation may be associated with species-specific immune and antiinflammatory functions.

His is known to increase gastric acid secretion and causes enlargement of the proventriculus (Harry et al., 1975). Consistent with previous reports, we found that His consumption resulted in increased proventricular weight and lesions with concurrent reductions in body weight and increased feed conversion. For example, Harry et al. (1975) and Barnes et al. (2001) fed chicks His at $0.1 \%$ to $1.0 \%$ and $0.1 \%$ to $0.2 \%$, respectively, and observed decreases in body weight and feed intake and an increase in the incidence of proventricular enlargement. Our data demonstrated that His induced several pathologies associated with proventriculitis of the glandular epithelium, fibrosis, or oedema. Interestingly, enlargement of the proventriculus was further related to inhibition of abdominal fat accumulation. ASX was found in high amounts in the liver, confirming that the liver was the main organ of metabolic activity, where ASX promotes expression of cytochrome P450 to facilitate hepatic drug metabolism (Takimoto et al., 2007). Moreover, His prevented ASX from being absorbed, resulting in reduced levels of ASX in the liver. Since our study involved a relatively small sample, our data may still be open for interpretation, particularly the data for SOD and TBARS. As with all studies involving ASX, the responses of various types of animals to the treatment may differ.

In conclusion, dietary supplementation with ASX influenced growth performance but did not affect lipid peroxidation in broiler chickens. Furthermore, ASX might be helpful to alleviate structural damages to the digestive systems of poultry under certain stressful conditions.

\section{CONFLICT OF INTEREST}

We certify that there is no conflict of interest with any financial organization regarding the material discussed in the manuscript.

\section{ACKNOWLEDGMENTS}

This work was carried out with the support of "Cooperative Research Program for Agriculture Science \& Technology Development (Project No. PJ005004)", Rural Development Administration, Republic of Korea.

\section{REFERENCES}

Akiba, Y., K. Sato, K. Takahashi, K. Matsushita, H. Komiyama, H. Tsunekawa, and H. Nagao. 2001. Meat color modification in broiler chickens by feeding yeast Phaffia rhodozyma containing high concentrations of astaxanthin. J. Appl. Poult. Res. 10:154-161.

Barnes, D. M., Y. K. Kirby, and K. G. Oliver. 2001. Effects of biogenic amines on growth and the incidence of proventricular lesions in broiler chickens. Poult. Sci. 80:906-911.

Bayyari, G. R., W. E. Huff, J. M. Balog, N. C. Rath, and J. N. Beasley. 1995. Experimental reproduction of proventriculitis using homogenates of proventricuiar tissue. Poult. Sci. 74:1799-1809.

Bell, J. G., J. McEvoy, D. R. Tocher, and J. R. Sargent. 2000. Depletion of $\alpha$-tocopherol and astaxanthin in Atlantic salmon (Salmo salar) affects autoxidative defense and fatty acid metabolism. J. Nutr. 130:1800-1808.

Brugh, M. and R. L. Wilson. 1986. Effect of dietary histamine on broiler chickens infected with avian reovirus S1133. Avian Dis. 30:199-203.

Chatterjee, I. B., S. D. Gupta, A. K. Majumder, B. K. Nandi, and N. Subramanian. 1975. Effect of ascorbic acid on histamine metabolism in scorbutic guinea-pigs. J. Physiol. 251:271-279.

Cheng, Y. H., T. F. Shen, V. F. Pang, and B. J. Chen. 2001. Effects of aflatoxin and carotenoids on growth performance and immune response in mule ducklings. Comp. Biochem. Physiol. C Toxicol. Pharmacol. 128:19-26.

Choi, S. K., Y. S. Park, D. K. Choi, and H. I. Chang. 2008. Effects of astaxanthin on the production of $\mathrm{NO}$ and the expression of COX-2 and iNOS in LPS-stimulated BV2 microglial cells. J. Microbiol. Biotechnol. 18:1990-1996.

Clemetson, C. A. 1980. Histamine and ascorbic acid in human blood. J. Nutr. 110:662-668.

Comhaire, F. H. and A. Mahmoud. 2003. The role of food supplements in the treatment of the infertile man. Reprod. Biomed. Online 7:385-391.

Das, D. and R. K. Banerjee. 1993. Effect of stress on the antioxidant enzymes and gastric ulceration. Mol. Cell Biochem. 125:115-125.

Desai, I. D. 1984. Vitamin E analysis methods for animal tissues. Methods Enzymol. 105:138-147.

Goto, S., K. Kogure, K. Abe, Y. Kimita, K. Kitahama, E. Yamashita, and H. Terada. 2001. Efficient radical trapping at the surface and inside the phospholipid membrane is responsible for highly potent antiperoxidative activity of the carotenoid astaxanthin. Biochim. Biophys. Acta. 1512:251-258.

Harry, E. G., J. F. Tucker, and A. P. Laursen-Jones. 1975. The role of histamine and fish meal in the incidence of gizzard erosion and pro-ventricular abnormalities in the fowl. Br. Poult. Sci. 16:69-78. 
Hix, L. M., S. F. Lockwood, and J. S. Bertram. 2004. Upregulation of connexin 43 protein expression and increased gap junctional communication by water soluble disodium disuccinate astaxanthin derivatives. Cancer Lett. 211:25-37.

Hussein, G., U. Sankawa, H. Goto, K. Matsumoto, and H. Watanabe. 2006. Astaxanthin, a carotenoid with potential in human health and nutrition. J. Nat. Prod. 69:443-449.

Hussein, G., H. Goto, S. Oda, T. Iguchi, U. Sankawa, K. Matsumoto, and H. Watanabe. 2005a. Antihypertensive potential and mechanism of action of astaxanthin: II. Vascular reactivity and hemorheology in spontaneously hypertensive rats. Biol. Pharm. Bull. 28:967-971.

Hussein, G., M. Nakamura, Q. Zhao, T. Iguchi, H. Goto, U. Sankawa, and H. Watanabe. 2005b. Antihypertensive and neuroprotective effects of astaxanthin in experimental animals. Biol. Pharm. Bull. 28:47-52.

Johnston, C. S. and S. N. Huang. 1991. Effect of ascorbic acid nutriture on blood histamine and neutrophil chemotaxis in guinea pigs. J. Nutr. 121:126-130.

Jyonouchi, H., S. Sun, K. Iijima, and M. D. Gross. 2000. Antitumor activity of astaxanthin and its mode of action. Nutr Cancer 36:59-65.

Kurihara, H., H. Koda, S. Asami, Y. Kiso, and T. Tanaka. 2002. Contribution of the antioxidative property of astaxanthin to its protective effect on the promotion of cancer metastasis in mice treated with restraint stress. Life Sci. 70:2509-2520.

Lyons, N. M. and N. M. O'Brien. 2002. Modulatory effects of an algal extract containing astaxanthin on UVA-irradiated cells in culture. J. Dermatol. Sci. 30:73-84.

Masumura, T., M. Sugahara, T. Noguchi, K. Mori, and H. Naito. 1985. The effect of gizzerosine, a recently discovered compound in overheated fish meal, on the gastric acid secretion in chicken. Poult. Sci. 64:356-361.

Miki, W. 1991. Biological functions and activities of animal carotenoids. Pure Appl. Chem. 63:141-146.

Naito, Y., K. Uchiyama, W. Aoi, G. Hasegawa, N. Nakamura, N. Yoshida, T. Maoka, J. Takahashi, and T. Yoshikawa. 2004. Prevention of diabetic nephropathy by treatment with astaxanthin in diabetic $\mathrm{db} / \mathrm{db}$ mice. Biofactors 20:49-59.

Nakano, M., A. Onodera, E. Saito, M. Tanabe, K. Yajima, J. Takahashi, and V. C. Nguyen. 2008. Effect of astaxanthin in combination with alpha-tocopherol or ascorbic acid against oxidative damage in diabetic ODS rats. J. Nutr. Sci. Vitaminol. 54:329-334.

Nishigaki, I., P. Rajendran, R. Venugopal, G. Ekambaram, D. Sakthisekaran, and Y. Nishigaki. 2010. Cytoprotective role of astaxanthin against glycated protein/iron chelate-induced toxicity in human umbilical vein endothelial cells. Phytother. Res. 24:54-59.
Ohgami, K., K. Shiratori, S. Kotake, T. Nishida, N. Mizuki, K. Yazawa, and S. Ohno. 2003. Effects of astaxanthin on lipopolysaccharide-induced inflammation in vitro and in vivo. Invest. Ophthalmol. Vis. Sci. 44:2694-2701.

Omaye, S. T., J. D. Turnbull, and H. E. Sauberlich. 1979. Selected methods for the determination of ascorbic acid in animal cells, tissues and fluids. Methods Enzymol. 62:3-11.

Palozza, P. and N. I. Krinsky. 1992. Antioxidant effects of carotenoids in vivo and in vitro: An overview. Methods Enzymol. 213:403-420.

Pegram, R. A. and R. D. Wyatt. 1981. Avian gout caused by oosporein, a mycotoxin produced by Caetomium trilaterale. Poult. Sci. 60:2429-2440.

Stuart, B. P., R. J. Cole, E. R. Waller, and R. E. Vesonder. 1986. Proventricular hyperplasia (malabsorption syndrome) in broiler chickens. J. Environ. Pathol. Toxicol. Oncol. 6:369-385.

Takahashi, K., M. Watanabe, T. Takimoto, and Y. Akiba. 2004. Uptake and distribution of astaxanthin in several tissues and plasma lipoproteins in male broiler chickens fed a yeast (Phaffia rhodozyma) with a high concentration of astaxanthin. Br. Poult. Sci. 45:133-138.

Takimoto, T., K. Takahashi, and Y. Akiba. 2007. Effect of dietary supplementation of astaxanthin by Phaffia rhodozyma on lipid peroxidation, drug metabolism and some immunological variables in male broiler chicks fed on diets with or without oxidised fat. Br. Poult. Sci. 48:90-97.

Tucker, J. F., E. G. Harry, and A. P. Laursen-Jones. 1975. The role of histamine and fish meal in the incidence of gizzard erosion and pro-ventricular abnormalities in the fowl. Br. Poult. Sci. 16:69-78

Uchida, K., M. Mitsui, and S. Kawakishi. 1989. Monooxygeneration of $\mathrm{N}$-acetylhistamine mediated by Lascorbate. Biochim. Biophys. Acta. 991:377-379.

Uchiyama, K., Y. Naito, G. Hasegawa, N. Nakamura, J. Takahashi, and T. Yoshikawa. 2002. Astaxanthin protects beta-cells against glucose toxicity in diabetic $\mathrm{db} / \mathrm{db}$ mice. Redox Rep. 7:290-293.

Vine, A. L., Y. M. Leung, and J. S. Bertram. 2005. Transcriptional regulation of connexin 43 expression by retinoids and carotenoids: similarities and differences. Mol. Carcinog. 43:75-85.

Wideman, R. F. Jr, Y. K. Kirby, G. R. Bayyari, T. L. Barton, W. E. Huff, P. Moore, and P. A. Dunn. 1995. Dietary copper in excess of $200 \mathrm{ppm}$ amplifies proventricular enlargement and dilation (proventriculitis/proventriculosis) in broilers. Poult. Sci. 74:85. 